\title{
Characterization of street food consumption in Palermo: possible effects on health
}

\author{
Silvio Buscemi ${ }^{1 *}$, Annamaria Barile ${ }^{1}$, Vincenza Maniaci ${ }^{1}$, John A Batsis ${ }^{2,3}$, Alessandro Mattina $^{1}$ and Salvatore Verga ${ }^{1}$
}

\begin{abstract}
Background: Street Food (SF) consists of out-of-home food consumption and has old, historical roots with complex social-economic and cultural implications. Despite the emergence of modern fast food, traditional SF persists worldwide, but the relationship of SF consumption with overall health, well-being, and obesity is unknown.

Methods: This is an observational, cross-sectional study. The study was performed in Palermo, the largest town of Sicily, Italy. Two groups were identified: consumers of SF $(n=687)$ and conventional restaurant food (RES) consumers $(n=$ 315). Study subjects answered a questionnaire concerning their health conditions, nutritional preferences, frequency of consumption of SF and a score relative to SF consumption ranging from 0 to 20 was calculated.
\end{abstract}

Results: Body mass index (BMl, $\left.\mathrm{kg} / \mathrm{m}^{2}\right)$ was significantly and independently correlated with the score of street food consumption $(r=0,103 ; p<0.002)$. The prevalence of different diseases, including hypertension and type 2 diabetes, and the use of medications did not differ between the two groups. Milza (a sandwich stuffed with thin slice of bovine spleen and lung) consumers had a significantly higher prevalence of hypertension $(12.2 \% \mathrm{vs} 6.2 \%$ in non consumers; $p<0.005)$ and in this subgroup the use of anti-hypertensive drugs was inversely correlated with the frequency of milza consumption $(r=0.11 ; P=0.010)$.

Conclusions: This study suggests that SF consumption in Palermo is associated with a higher BMI and higher prevalence of hypertension in milza consumers. Further studies should evaluate whether frequent SF consumers have unfavourable metabolic and cardiovascular profile.

\section{Introduction}

The increasing prevalence of obesity [1] and other cardiovascular risk factors [2] have been partially attributed to changing nutritional habits and reduced level of regular physical activity. The obesity epidemic is also influenced by social network phenomena characterized by behavioural person-to-person interactions [3]. Fast food consumption, defined as inexpensive food, sold by means of self-service systems or carry-out eating locales without waiter service [4], has been implicated as one potential reason for this epidemic [5,6]. It is energy dense, poor in nutritional and fibre content, high in glycemic load and often associated with large portion sizes $[4,7]$.

Closely linked to fast food is another version of out-ofhome food consumption termed Street Food (SF). This

\footnotetext{
* Correspondence: silbus@tin.it

'Department of Medicina Interna e Specialistica (DIMIS), Faculty of Medicine University of Palermo (Italy) - Policlinico "P.Giaccone", via del vespro, 129 - I90127 Palermo, Italy

Full list of author information is available at the end of the article
}

entity has old, historical roots with complex socialeconomic and cultural implications [8]. Street food is present even in less developed countries, and has occasionally been considered to be the hallmark of the early development of fast food $[9,10]$. It is quickly available and consumed, and generally affordable to large parts of the population.

Despite the emergence of modern fast food, traditional street food persists worldwide, especially in Europe and in Mediterranean countries [Maniaci V. Il cibo di strada e la comunità palermitana: indagine circa gli aspetti nutrizionali. University of Palermo, degree thesis for dietician, 2009]. In a broad sense, street food has often been described as having some elements of the Mediterranean Diet $[11,12]$. Few studies exist that consider the health and psychological effects of street food consumption in habitual consumers [13-26]. To our knowledge, no study has ever considered the relationship of street food consumption in the western world with overall health, well-being, 
and obesity. We undertook this study to characterize this relationship.

\section{Methods}

This observational, cross-sectional study was performed in Palermo, the largest town of Sicily, Italy, with a population of 663.173 inhabitants. We identified two groups: consumers of SF and a control group consisting of conventional restaurant food consumers (RES). Subjects of the SF group were recruited among customers of a historical district of Palermo where SF is traditionally served (Antica Focacceria San Francesco, Palermo). RES subjects were recruited concurrently in the same time period, day of week, and hour of day as the SF group, in four restaurants quoted in specialized guides and present in the center of Palermo, where it is possible to consume complete meals according to a conventional sit-down dinner menu based on usual Mediterranean foods. These restaurants were contacted by the Confcommercio-FIPE, the representative organization of commercial activities. All restaurants permitted the study staff to approach and survey their customers.

From 17th September until 19th October 2009, every Thursday through Sunday, groups composed of physicians and dieticians asked study subjects to answer a questionnaire concerning their health conditions, general nutritional/dietary preferences/habits, usual frequency of consumption of SF or of foods offered on the restaurant menu in the past year. When requested, interviewers assisted customers in completing the questionnaire $(<10 \%$ of cases) when subjects requested information about diseases or medication consumption. In no case did the operators complete the questionnaires for the subjects. The four page questionnaire was administered in the Italian language, and was intended to be completed between 2-4 minutes. Inclusion criteria were subjects aged $\geq 18$, born and resident in Palermo. We therefore excluded those participants $<18$ years old, those who were not born in Palermo or non-residents of Palermo. There was no incentive provided to the subjects.

Height was listed on their national identify card when available (59\%) or self-reported (41\%). Self-reported body weight was listed on their registration card or directly obtained if requested by the subjects (22\%) by means of a portable weight balance (SECA, cursa 818; Hamburg, Germany); body mass index (BMI) was calculated as body weight $(\mathrm{kg}) /$ height $^{2}(\mathrm{~m})$.

An approved informed consent form was signed by each subject. The study protocol was approved by the Ethics Committee of the University Hospital Policlinico P. Giaccone of Palermo, Italy, and by the Committee for the Protection of Human Subjects at Dartmouth College, USA.

\section{Description of Street Food}

The consumption of street food specialties unique to Palermo's tradition were considered [Maniaci V. Il cibo di strada e la comunità palermitana: indagine circa gli aspetti nutrizionali. University of Palermo, degree thesis for dietician; 2009] as briefly described in Table 1. A more complete gastronomic and nutritional description of street food specialties of Palermo's is available at the web address http://www.scribd.com/doc/60786261/ Palermo-Street-Food. Subjects were asked if they consumed each of these foods (yes/not); self-reported frequency of consumption of each food was categorized less than or greater than once a month. Each of the 10 considered foods was scored $0=$ never consumed, $1=$ once a month or less, 2 = more than once a month; the sum of single scores ranged therefore from 0 and 20.

\section{Co-Morbid conditions}

All subjects answered questions relative to regular medication consumption and concomitant diseases specifically concerning the presence of the following: hypertension, type 1 and type 2 diabetes mellitus, dyslipidemia, coronary heart disease, stroke, gastro-intestinal diseases including dyspepsia, gastric or duodenal ulcers, hiatal hernia, inflammatory bowel disease, gallstones, kidney stones, chronic renal failure, chronic respiratory diseases,. Subjects were also asked whether they had followed a low calorie diet, and if so, whether it was prescribed by a health professional or was self-initiated. Finally, subjects were asked whether they ever used weight-loss medications. Medications were self-reported with their trade name and a physician coded each drug in its respective category.

\section{Statistic analysis}

All data are expressed as mean $\pm \mathrm{sd}$ or as prevalence (\%). Variables relative to single food consumption, diseases and drug categories were dichotomized $(1=$ yes; $2=$ no). Continuous variables were assessed using Student's unpaired $t$-test and categorical variables using Pearson's $\chi 2$ test. Linear regression analysis assessed the relationships between variables; the independency of associations between variables was assessed using multiple regression analysis. A two-tailed $\mathrm{p}<0.05$ was considered statistically significant. Normal distribution of continuous variables was tested by the Kolmogorov-Smirnow test. All analyses were performed using SYSTAT (Windows version 11.0; Systat Software Inc., San Jose, CA, USA).

\section{Results}

Of a total of 1,002 subjects with complete data, the SF group consisted of 687 subjects and RES group 315 subjects (Figure 1). Age, height, weight and BMI were normally distributed. 
Table 1 Description of street food specialties of Palermo's tradition

\begin{tabular}{|c|c|}
\hline Food & Description \\
\hline Panelle & pancakes of chickpeas flour \\
\hline Rascatura & obtained from the residual panelle's dough left in the edges of the patty used to cook them \\
\hline Crocchè & fried cylinders of mashed potatoes \\
\hline Arancine & fried rice spheres stuffed with sauce and meat or mozzarella cheese and ham \\
\hline $\begin{array}{l}\text { Focaccia with } \\
\text { milza }\end{array}$ & $\begin{array}{c}\text { a sandwich stuffed with thin slice of bovine spleen and lung, ricotta cheese and slivers of caciocavallo, very savoury oblong- } \\
\text { shaped cheese of Southern Italy }\end{array}$ \\
\hline Sfincione & a soft leavened dough seasoned with tomato, anchovies, onion, olive oil and oregano \\
\hline Frittola & $\begin{array}{c}\text { consists of small pieces of fat, cartilages and bit of meat detached by the discards of slaughter that, first of all, are fried and } \\
\text { then boiled }\end{array}$ \\
\hline $\begin{array}{l}\text { Musso and } \\
\text { Quarume }\end{array}$ & $\begin{array}{l}\text { the feet, the jaw, the breast and other parts of the calf cut into bits and boiled, they constitute the musso; the same } \\
\text { ingredients of the musso can be served with vegetable broth and in this way they are called the quarume. }\end{array}$ \\
\hline Stigghiole & guts of calf twisted into strips of fat and onion, pierced in a spit and roasted \\
\hline
\end{tabular}

\section{Demographics}

Demographic characteristics are reported in Table 2. The group's marital status differed and the number of offspring was significantly higher in the SF group. The SF group had a higher prevalence of unemployed and employed subjects and of housewives.

\section{Food preferences}

The score of street food consumption significantly ( $\mathrm{F}=$ 3.44; $\mathrm{p}<0.005$ ) changed according to the employment status (Figure 2). The prevalence of subjects who reported following at least one low calorie diet in their lifetime was no different between groups $(p=0.053)$, despite a higher percentage of subjects in the SF who had followed a self-prescribed diet. The SF score was $5.1 \pm$ 3.8 with a median value of 5 (range $0-20$ ); interquartile ranges were, respectively, $1^{\text {st }}$ quartile: $0-1 ; 2^{\text {nd }}$ quartile: $2-$ $4 ; 3^{\text {rd }}$ quartile: $5-6,4^{\text {th }}$ quartile: 7-20. SF consumption score was higher in the SF group $(6.6 \pm 3.5$ [median 6.0; range of 1-20] vs $1.8 \pm 2.2$ [median 1.0; range of $0-10$ ]; $\mathrm{P}<0.001$ ), yet overall, both groups consumed each street food with the same order of preference (Additional file 1 Table A). Beer (46.4 vs. 8.9\%; p < 0.001) and soft drinks ( 31.9 vs. $11.4 \%$; $<<0.001$ ) were the preferred beverages in SF subjects, while water $(14.4$ vs $36.8 \%$; $p<0.001)$ and wine ( 7.3 vs. $42.9 \%$; p < 0.001 ) were consumed more often in RES subjects. No significant correlation was observed between the score of SF consumption and any of the diseases considered in the study. Age was inversely and independently correlated with the score of street food consumption $(r=-0.069 ; \mathrm{p}<0.05)$.

\section{Health and foods}

The SF group had a significantly higher BMI than the RES group (Table 2). BMI was significantly and independently correlated with the score of street food consumption (Figure 3, Table 3), and independently associated with age, sex, and offspring number (Table 3 ) that gave an $\mathrm{R}^{2}=0.26$. The correlation between $\mathrm{BMI}$ and the score of street food consumption was significant $(\mathrm{r}=0.10$; $\mathrm{p}<$ 0.05 ) also in addition to considering only the subjects of the SF group. In this latter group, the BMI increased significantly across the tertiles of street food score (23.8 \pm 4.3 vs $23.9 \pm 4.0$ vs $\left.24.7 \pm 4.1 \mathrm{~kg} / \mathrm{m}^{2} ; \mathrm{F}=3.42 ; \mathrm{p}<0.05\right)$, with third tertile significantly different $(\mathrm{p}<0.05)$ from first and second tertiles respectively. The SF score was independently correlated with age, sex, and body weight (Table 4). The presence of at least one disease was independently associated with age, sex and BMI (Table 3) that gave an $\mathrm{R}^{2}=0.11$.

Hypertension was independently associated with age $\left(\mathrm{R}^{2}=0.15\right.$; Table 3$)$. Milza consumers $(\mathrm{n}=599)$ had a significantly higher prevalence of hypertension than non consumers $(n=405)(12.2$ vs $6.2 \%$; $<0.005)$ and in this subgroup the use of anti-hypertensive drugs was inversely correlated with the frequency of milza consumption $(\mathrm{r}=$ $0.11 ; \mathrm{p}<0.01$ ). Disease prevalence and medication usage were comparable between the two groups (Additional file 1 Table B and C). By combining all subjects into two groups according to the median value of SF score or by using tertiles of SF score, no significant difference was observed in any disease rate (data not shown).

\section{Discussion}

Our findings suggest that subjects who consume Street food are associated with higher prevalence rates of BMI and hypertension than the restaurant eating group. We observed a relationship between SF consumption and BMI supporting the hypothesis that SF may be a proxy indicator of other components of an unhealthy lifestyle as behaviours have been documented to aggregate [27]. These results parallel those previously reported for fast food $[4,6]$ suggesting that frequent consumption of street food is equally an unhealthy behaviour.

Despite significant, the influence of SF consumption was rather limited. We demonstrated that body weight was a highly significant predictor of elevated SF score. We additionally examined whether SF score predicted 


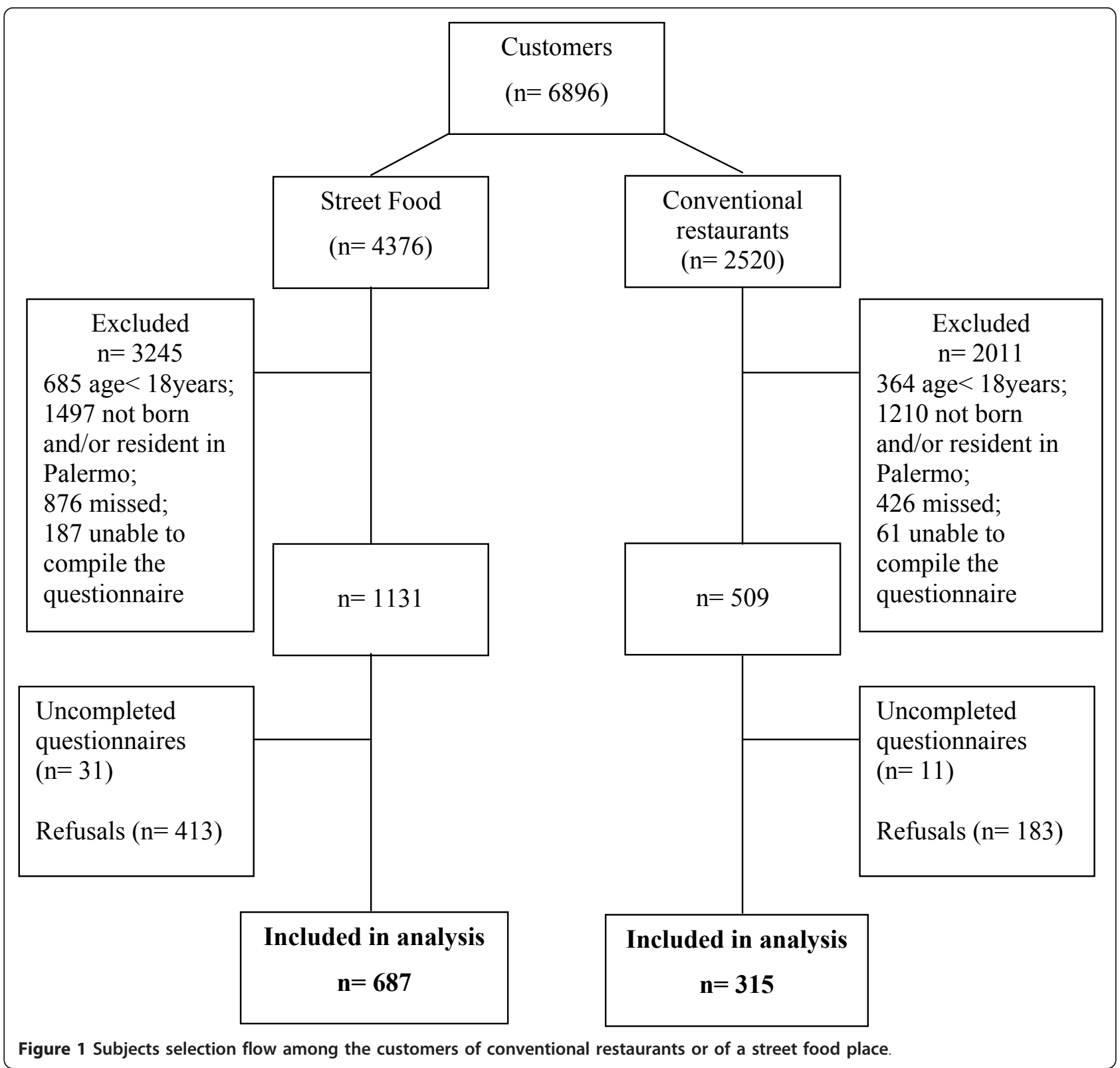

other outcomes including body mass index. These results may indicate that a diet that includes SF consumption may lead to reduction of other possible healthier foods. Additionally, these results provide preliminary information that the relationship with weight/obesity may in fact be bi-directional. Both the number of SF specialities consumed and the frequency of their consumption may influence the SF score. Subjects in the highest quartile of $\mathrm{SF}$ score reported values $\geq 7$. From the regression analysis (Table 4), approximately $100 \mathrm{~kg}$ of body weight were associated with 2 points of SF score, corresponding to the habitual consumption of two specialties of SF once a month or less or, alternatively, to the consumption of one specialty of SF more than once a month. Therefore, the SF score probably reflects a tendency towards a nutritional style rather than the amount of habitual energy intake. However, further validation studies would be needed to better examine this relationship.

The relationships between SF consumption, BMI and health status may have been influenced by a selection bias that is hardly avoidable in similar studies. Subjects frequenting the SF place and restaurants respectively, may differ, mainly on socioeconomic characteristics, yet specific data other than employment was not canvassed. Observed differences (Table 2) concerning employment, marital status and offspring number may also reflect such differences in outcomes independently from dietary factors. The SF score changed according to employment status so thus 


\begin{tabular}{|c|c|c|c|}
\hline & \multicolumn{2}{|c|}{ Groups } & \multirow[b]{2}{*}{$P^{2}$} \\
\hline & Street Food & Restaurant & \\
\hline males/females ( $n$ ) & $321 / 366$ & $141 / 174$ & 0.61 \\
\hline age (years) & $37.6 \pm 13.8$ & $37.9 \pm 14.1$ & 0.75 \\
\hline body weight $(\mathrm{kg})$ & $69.9 \pm 14.8$ & $68.5 \pm 15.8$ & 0.17 \\
\hline $\mathrm{BMI}\left(\mathrm{kg} / \mathrm{m}^{2}\right)$ & $24.3 \pm 4.1$ & $23.7 \pm 4.4$ & $<0.05$ \\
\hline marital status (\%): & & & $<0.005$ \\
\hline single & 44.4 & 47.3 & \\
\hline married & 51.1 & 47.4 & \\
\hline divorced & 2.9 & 3.8 & \\
\hline widow/er & 1.6 & 1.5 & \\
\hline offspring (n) & $1.1 \pm 1.3$ & $0.8 \pm 1.0$ & $<0.001$ \\
\hline employment status (\%): & & & $<0.001$ \\
\hline student & 21.6 & 25.0 & \\
\hline unemployed & 3.4 & 1.7 & \\
\hline housewife & 13.4 & 6.0 & \\
\hline employed & 42.7 & 37.5 & \\
\hline manager/professional & 14.9 & 26.7 & \\
\hline retired & 4.0 & 3.1 & \\
\hline smokers (\%) & 35.0 & 33.3 & 0.67 \\
\hline previous diet therapy (\%): & & & 0.053 \\
\hline self-prescribed & 31.9 & 27.9 & \\
\hline prescribed & 20.2 & 27.0 & \\
\hline previous or current use of weight-reduction medications (\%) & 6.1 & 4.4 & 0.36 \\
\hline
\end{tabular}

${ }^{1}$ Mean \pm sd or percentage. ${ }^{2}$ Student's unpaired $t$-test or Pearson's $\chi^{2}$ test, as appropriate. BMl: body mass index.

manager and professionals had a significantly lower consumption of street food than the employed (Figure 2). Unfortunately, we were unable to further parse the data in this group to further explore this association. The significant positive correlation between the SF score and BMI even within the SF group leads us to believe sampling bias may not be socioeconomic related suggesting that diet style influenced body size probably independently from socioeconomic status.

Our study describes the consumption of local traditional SF on obesity and medical illnesses and is unique in that it addresses a critical knowledge gap. Our study, to our knowledge, is the first to describe such patterns in a European city. Such information is currently only available for modern fast food consumption [4,28]. Our results further the understanding that SF has possibly contributed to the sustainability of low-income people and is analogous to modern fast food for the effects on some aspects concerning health. Furthermore, these results may be useful in targeting future specific interventions in our local geographic area.

The few published studies on SF have exclusively considered only the description of food, chemical or microbiological contaminants [13-18], its limited nutritional value $[19,20,29]$ or have been described anecdotally $[21,22]$. In general, street food consumption is perceived as an unhealthy behaviour [23] which exerts a strong appeal [24] and may be advisable to limit its consumption. It has been also described that is in some cases, subjects underwent psychological conditioning strategies for decreasing SF consumption $[25,26]$.

Despite the wide availability of SF in the study region, we recruited the SF group in the oldest place of SF consumption of Palermo which now functions as a SF restaurant to obtain a more homogeneous and comparable group with respect to the group RES. The manner in identifying subjects reduces, to one extent, the possible psycho-social-cultural confounding factors (for instance alcohol abuse or very low income). The frequency of different street food consumption was similar in both groups, suggesting that the Palermo's street food consumption is a diffuse cross-cultural and socio-cultural phenomenon. Our results also suggest that as one ages, SF consumption is reduced as has previously been demonstrated whereby eating habits become healthier with aging $[30,31]$.

This study has some important limitations. Our data is self-reported and subject to recall and measurement bias. While we relied on these self-reported measures, undoubtedly this introduces bias as to the accuracy of the values/medications reported. Structured interviews and assessments would be required, which would not be 
Street food score

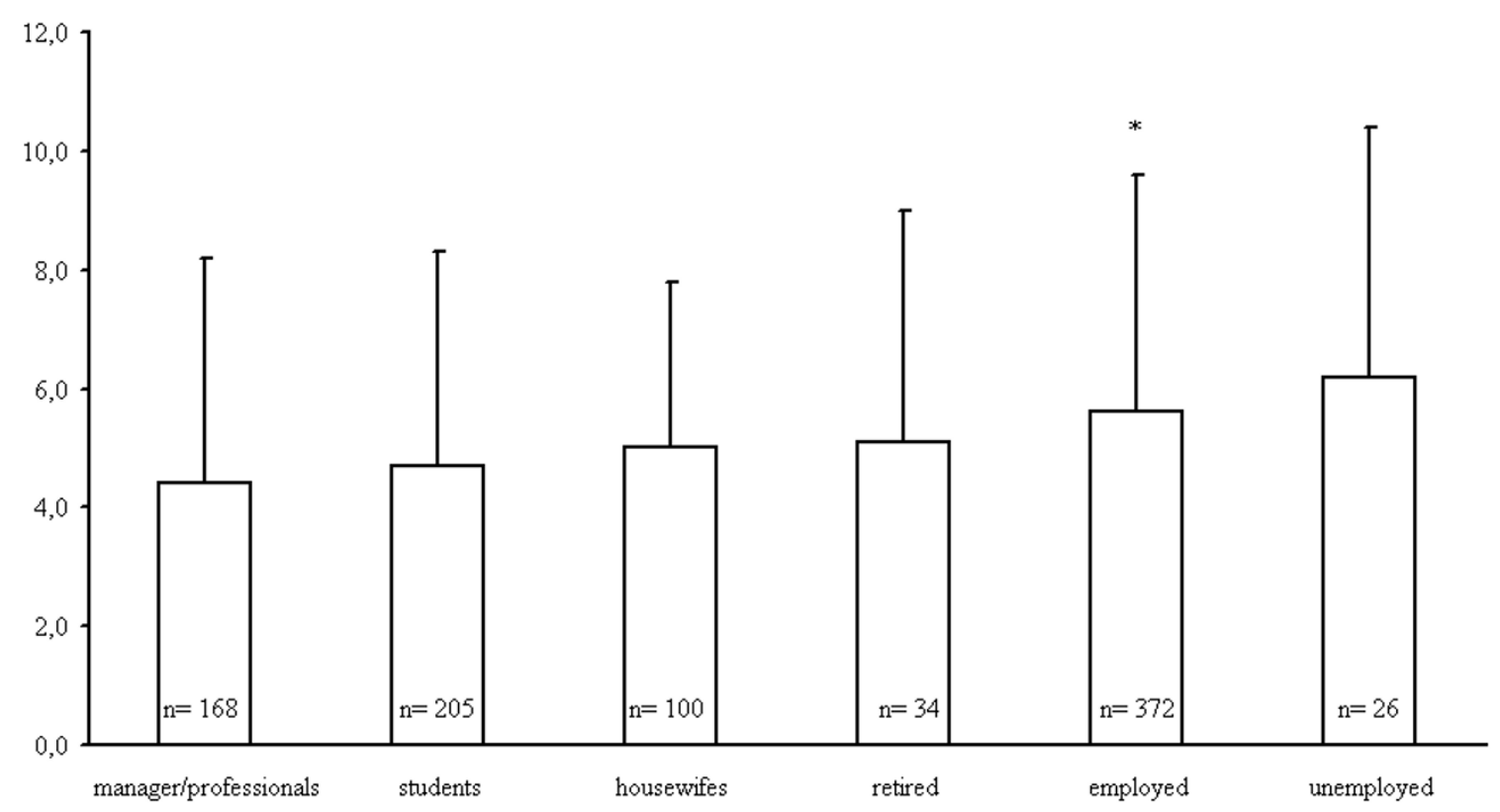

ANOVA: $\mathrm{F}=3.44, \mathrm{P}<0.005$ with $* \mathrm{P}<0.05$ vs. manager professionals

97 subjects refused to give information about their employment status

Figure 2 Street food score and employment status.

practical in this study protocol. However, the manner in which we ascertained the data was similar in both groups and emerging data does suggest that self-reported BMI may be accurate [32]. Trust in the health-care system is known to be related to self-rated health $[33,34]$. Recent investigations demonstrate that Italians hold trust in their national health care system [35] and we are hopeful that less reporting bias concerning self-rated health may have occurred in this study. The manner in recruiting the two groups directly in the place of food consumption did not allow further clinical data gathering; we were also limited in time by needing to ask our questionnaire in only a few minutes. Studies have demonstrated that short surveys often have higher completion rates [36]. We acknowledge that the demographic characteristics of each group differed, which may account for participant's response to questions and may be reflective in their food consumption.

Other factors, including time of the year may influence the extent of SF consumption. Nonetheless, the comparability of anthropometric and demographic characteristics and its relationship to SF consumption is unique to our own study. Finally, the calculated SF score was not validated but still provides interesting information. The SF score has other intrinsic limitations, for instance someone who eats street food most days of the week but only eats one item would only have a score of 2 , however we may consider this as an extreme situation that is expected to have no high influence on the results given the relatively high number of subjects included in this study. We acknowledge that further validation studies would be needed to allow an accurate interpretation of what an elevated SF score means.

Due to our sampling strategy, the study cannot be generalized and our results must be referred only to local people whose nutritional habits include different degree of street food consumption. Whether our results parallel similar food practices in other countries is unknown but may be a subject for further investigation.

The prevalence of hypertension and diabetes (Additional file 1 Table B) was lower than that in the general local population $[37,38]$. Studies have shown that those with diagnosed hypertension and diabetes tend to have better eating habits than those with undiagnosed disease [39-41]. The study subjects were younger than in the general population who have been documented to have poor eating habits [42]. Secondly, our data is self-reported and subject to recall and measurement bias.

Although we describe associations of specific foods with given medical conditions, our data needs to be confirmed with longitudinal studies. The higher prevalence of hypertension in subjects eating focaccia with milza may be linked with the fact that this food is cooked with lard, and is characterized with high contents of saturated 


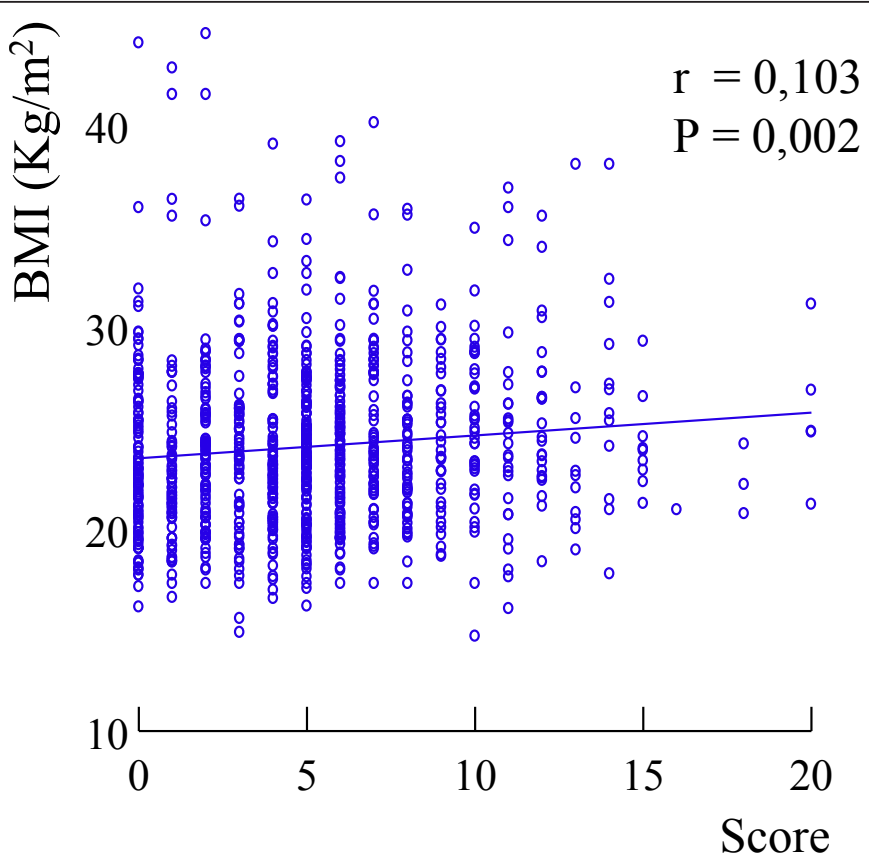

Figure 3 Correlation between the score of street food consumption and body mass index (BMI).

Table 3 Independent predictors by multiple regression analysis of BMI, presence of at least one of the considered diseases and hypertension.

\begin{tabular}{llcc}
\hline \multicolumn{4}{l}{ Variables } \\
\hline Outcome & Independent variable & coefficient $\boldsymbol{\beta}$ & $\mathbf{P}$ \\
\hline BMI & & & \\
& constant & 25.037 & $<0.001$ \\
& age (years) & 0.071 & $<0.001$ \\
& sex (1 = m; 2 = f) & -2.862 & $<0.001$ \\
& street food (score) & 0.064 & $<0.05$ \\
& offspring (n) & 0.503 & $<0.001$
\end{tabular}

Diseases

$(1$ = yes; 2 = not $)$

$\begin{array}{lcc}\text { constant } & 2.415 & <0.001 \\ \text { age (years) } & -0.010 & <0.001 \\ \text { sex }(1=\mathrm{m} ; 2=\mathrm{f}) & -0.085 & <0.01 \\ \text { BMI } & -0.010 & <0.01 \\ \text { street food (score) } & -0.001 & 0.715\end{array}$

Hypertension

$(1$ = yes; 2 = not $)$

\begin{tabular}{lcc} 
constant & 2.169 & $<0.001$ \\
age (years) & -0.008 & $<0.001$ \\
sex $(1=\mathrm{m} ; 2=\mathrm{f})$ & 0.028 & 0.127 \\
street food (score) & -0.001 & 0.632 \\
\hline
\end{tabular}

BMI: body mass index; $m=$ male; $f=$ female.

Diseases: at least one of the following: hypertension, type 1 and type 2

diabetes mellitus, dyslipidemia, coronary heart disease, stroke, gastro-intestinal

diseases including dyspepsia, gastric or duodenal ulcers, hiatal hernia,

inflammatory bowel disease, gallstones, kidney stones, chronic renal failure,

chronic respiratory diseases

Variables coded as 2 are the reference category. fatty acids. These entities are associated with oxidative stress, endothelial dysfunction and cardiovascular risk $[43,44]$. On the contrary, the main ingredient of panelle is chick-pea floor that is rich in polyunsaturated fatty acids, that of arancine is rice and potatoes are the main ingredient of crocchè. Yet without knowing the exact nutritional content of each of the foods concerned in our study, our statements are purely speculative.

\section{Conclusions}

SF consumption may be associated with elevated BMI and prevalence of hypertension and appears to be a diverse nutritional habit in all socioeconomic strata. This study outlines a possible approach for defining and recognizing specific social-environmental aspects of population nutritional culture that are now recognized to have an important role in supporting health-promoting patterns of behaviour [45]. Our results are not meant to be definitive in nature, but exploratory due to sample size limitations. Further studies should evaluate whether frequent street

Table 4 Independent Predictors of the street food score by linear regression model

\begin{tabular}{ccc}
\hline Variables & coefficient $\boldsymbol{\beta}$ & $\mathbf{P}$ \\
\hline constant & 6.1 & $<0.001$ \\
age (years) & -0.03 & 0.004 \\
sex $(1=\mathrm{m} ; 2=\mathrm{f})$ & -0.99 & 0.002 \\
body weight $(\mathrm{kg})$ & 0.02 & 0.016 \\
\hline
\end{tabular}

$\mathrm{m}=$ male; $f=$ female 
food consumers have unfavourable metabolic and cardiovascular profile.

\section{Additional material}

Additional file 1: Tables A, B and C. The file contains data concerning the street food preferences, the prevalence of reported diseases and the use of medications in the two cohorts of Street Food consumers and of Restaurant Food consumers.

\section{List of abbreviations}

BMI: body mass index; RES: conventional restaurant food; SF: street food.

\section{Author details}

${ }^{1}$ Department of Medicina Interna e Specialistica (DIMIS), Faculty of Medicine University of Palermo (Italy) - Policlinico "P.Giaccone", via del vespro, 129 - I90127 Palermo, Italy. ${ }^{2}$ Dartmouth College, Hanover, New Hampshire, USA. ${ }^{3}$ Section of General Internal Medicine, Dartmouth-Hitchcock Medical Center, Lebanon, New Hampshire, USA.

\section{Authors' contributions}

SB was the main author of the manuscript and contributed to the design of the study, preparation of protocols, statistical analyses, interpretation of data and preparation of the manuscript. $A B$ contributed to preparation of protocols, data collection and interpretation of data. VM contributed to preparation of protocols, data collection and interpretation of data. JAB contributed to the interpretation of data and preparation of the manuscript. AM contributed to data collection and preparation of the manuscript. SV contributed to interpretation of data and preparation of the manuscript. All authors read and approved the final manuscript.

\section{Competing interests}

The authors declare that they have no competing interests.

Received: 5 February 2011 Accepted: 28 October 2011

Published: 28 October 2011

\section{References}

1. National Center for Health Statistics: Prevalence of overweight and obesity among adults: United States, 1992-2002. Center for Disease Control. [http://www.cdc.gov/nchs/products/pubs/pubd/hestats/obese/obse99.htm], via the INTERNET. Accessed 2010 July 11.

2. Batsis JA, Nieto-Martinez RE, Lopez-Jimenez F: Metabolic syndrome: from global epidemiology to individualized medicine. Clin Pharmacol Ther 2007, 82:509-524.

3. Christakis NA, Fowler $\mathrm{JH}$ : The spread of obesity in a large social network over 32 Years. N Engl J Med 2007, 357:370-379.

4. Pereira MA, Kartashov Al, Ebbeling CB, Van Horn L, Jacobs DR Jr, Ludwig DS: Fast-Food Habits, Weight Gain, and Insulin Resistance (the CARDIA Study): 15-year prospective analysis. Lancet 2005, 365:36-42.

5. Jeffery RW, Baxter J, McGuire $M$, Linde J: Are fast food restaurants an environmental risk factor for obesity? Int J Behav Nutr Phys Act 2006, 3:2-12.

6. Rosenheck R: Fast food consumption and increased caloric intake: a systematic review of a trajectory towards weight gain and obesity risk. Obesity Rev 2008, 9:535-547.

7. Isganaitis E, Lustig RH: Fast food, central nervous system, insulin resistance, and obesity. Arterioscler Thromb Vasc Biol 2005, 25:2451-2462.

8. Parente G: Cibo veloce e cibo di strada. Le tradizioni artigianali del fastfood in Italia alla prova della globalizzazione. Storicamente 2007, 3[http:// www.storicamente.org/03parente.htm], via the INTERNET. Accessed 2010 July 11.

9. Pitte JR: Nascita e diffusione dei ristoranti. In Storia dell'alimentazione. Edited by: Flandrin JL, Montanari M. Bari (I): Laterza; 1997:601-612.

10. Winarno $F G$, Allain A: Street foods in developing countries: lessons from Asia. FAO Corporate Document Repository 2009 [http://www.fao.org/docrep/ u3550t/u3550t08.htm], via the INTERNET. Accessed 2010 July 11.
11. Teti V: Alimentazione nel Mezzogiorno continentale. La Dieta Mediterranea: modello ideale e realtà. /l colore del cibo. Geografia, mito e realtà dell'alimentazione mediterranea Roma: Melteni; 1999, 34-46.

12. Bifulco $M$, Caruso MG: From the gastronomic revolution to the new globesity epidemic. J Am Diet Assoc 2007, 107:2058-2060.

13. Barro N, Ouattara CA, Nikiema PA, Ouattara AS, Traoré AS: Microbial quality assessment of some street food widely consumed in Ouagadougou, Burkina Faso. Sante 2002, 12:369-374.

14. Azanza MP, Gatchalian CF, Ortega MP: Food safety knowledge and practices of streetfood vendors in a Philippines university campus. Int $J$ Food Sci Nut 2000, 51:235-246.

15. Rheinlander $T$, Olsen M, Bakang JA, Takyi H, Konradsen F, Samuelsen $H$ : Keeping up appearances: perceptions of street food safety in urban Kumasi, Ghana. J Urban Health 2008, 85:952-964

16. Ortiz-Trejo JM, Correa-Chacon AJ, Sctelo-Ham El, Torres-Valenzuela A, Alvarado-Esquivel C: Risk factors associated with neurocysticercosis in a public hospital in Mexico. Gac Med Mex 2006, 142:175-179.

17. Vollard AM, Ali S, van Asten HA, Ismid IS, Widjaja S, Visser LG, Surjadi Ch, van Dissel JT: Risk factors for transmission of foodborne illness in restaurants and street vendors in Jakarta, Indonesia. Epidemiol Infect 2004, 132:863-872

18. Lim-Quizon MC, Benabaye RM, White FM, Dayrit MM, White ME: Cholera in metropolitan Manila: foodborne transmission via street vendors. WHO Bulletin 1994, 72:745-749.

19. Jackson P, Romo MM, Castillo MA, Castillo-Duran C: Junk food consumption and child nutrition. Nutritional anthropological analysis. Rev Med Chil 2004, 132:1235-1242.

20. van 't Riet $H$, den Hartog AP, Mwangi AM, Mwadime RKN, Foeken DWJ, van Staveren WA: The role of street foods in the dietary pattern of two lowincome groups in Nairobi. Eur J Clin Nutr 2001, 55:562-570.

21. Jean LA: Finger food menu restores independence in dining. Health Care Food Nutr Focus 1997, 14:4-6.

22. Schwerthoffer D, Bauml J: Junk-food-intervention in poisoning delusion. Psychiatr Prax 2007, 34:400-402.

23. Corley G, Demarest-Litchford M, Bazzarre TL: Nutrition knowledge and dietary practices of college coaches. J Am Diet Assoc 1990, 90:705-709.

24. Logue AW, Smith ME: Predictors of food preferences in adult humans. Appetite 1986, 7:109-125.

25. Clapham K, Abramson EE: Eversive conditioning of junk food consumption: a multiple vaseline study. Addict Behav 1985, 10:437-440

26. McNamara JR, Green JP: Decreasing junk-food consumption through the use of self-management procedures: a case study. Psychol Rep 1991, 69:19-22.

27. Malik VS, Schulze MB, Hu FB: Intake of sugar-sweetened beverages and weight gain: a systematic review. Am J Clin Nutr 2006, 84:274-288.

28. Morgenstern LB, Escobar JD, Sanchez BN, Hughes R, Zuniga BG, Garcia N, Lisabeth LD: Fast food and neighbourhood stroke risk. Ann Neurol 2009, 66:165-170.

29. Ag Bendech M, Chaulial M, Gerbouin-Rerolle P, Malvy D: Home and outside home food complementarity in Bamako (Mali): nutritional and economic aspects. What is the rationality behind consumers'choices? Rev Epidemiol Sante Publique 1999, 47:151-164.

30. Drewnowski A: Sensory control of energy density at different life stages. Proc Nutr Soc 2000, 59:239-244.

31. Drewnowski A, Shultz JM: Impact of aging on eating behaviors, food choices, nutrition, and health status. J Nutr Health Aging 2001, 5:75-79.

32. Dekkers JC, van Wier MF, Hendriksen IJ, Twisk JW, van Mechelen W: Accuracy of self-reported body weight, height and waist circumference in a Dutch overweight working population. BMC Med Res Methodol 2008, 8:69-82.

33. Mohseni M, Lindstrom M: Social capital, trust in the health-care system and self-rated health: the role of access to health care in a populationbased study. Soc Sci Med 2007, 64:1373-1383.

34. Yang TC, Matthews SA, Shoff C: Individual Health Care System Distrust and Neighborhood Social Environment: How Are They Jointly Associated with Self-rated Health? J Urban Health 2011

35. Osservatorio sanità di Unisalute: Italiani, fiducia (quasi) cieca nella sanità pubblica.[http://www.unisalute.it/portal/page/portal/UNISALUTE_CA/FLD _COMUNICATISTAMPA/

FLD_CST_99_20110411_ITALIANIFIDUCIANELLASALUTE/Italiani\%20e\%20fiducia $\% 20$ nella\%20salute_5-04-2011.pdf], via the INTERNET. Accessed 200724 July. 
36. Lund E, Gram IT: Response rate according to title and length of questionnaire. Scand J Soc Med 1998, , 26: 154-60.

37. Rapporto Regionale PASSI 2005. [http://www.doesicilia.it], via the INTERNET. Accessed 2010 July 11.

38. ISS: Progetto Cuore.[http://www.cuore.iss.it], via the INTERNET. Accessed 2010 July 11.

39. Neuhouser ML, Miller DL, Kristal AR, Barnett MJ, Cheskin LJ: Diet and exercise habits of patients with diabetes, dyslipidemia, cardiovascular disease or hypertension. J Am Coll Nutr 2002, 21:394-401.

40. The Diabetes Prevention Program Research Group: Reduction in the incidence of type 2 diabetes with lifestyle intervention or metformin. $N$ Engl J Med 2002, 346:393-403.

41. Appel LI, Moore TJ, Obarzanek E, Vollmer WM, Svetkey LP, Sacks FM, Bray GA, Vogt TM, Cutler JA, Windhauser MM, Lin PH, Karanja N: A clinical trial of the effects of dietary patterns on blood pressure. DASH Collaborative Research Group. N Engl I Med 1997, 336:1117-1124.

42. Lappalainen R, Saba A, Holm L, Mykkanen H, Gibney MJ, Moles A: Difficulties in trying to eat healthier: descriptive analysis of perceived barriers for healthy eating. Eur J Clin Nutr 1997, 51(s2):S36-40.

43. Williams MJ, Sutherland WH, McCormick MP, de Jong SA, Walzer RJ, Wilkins GT: Impaired endothelial function following a meal rich in used cooking fat. J Am Coll Cardiol 1999, 33:1050-1055.

44. Mann Jl: Diet and risk of coronary heart disease and type 2 diabetes. Lancet 2002, 360:783-789.

45. Booth DA, Booth P: Targeting cultural changes supportive of the healthiest lifestyle patterns. A biosocial evidence-base for prevention of obesity. Appetite 2011, 56:210-221.

doi:10.1186/1475-2891-10-119

Cite this article as: Buscemi et al: Characterization of street food consumption in Palermo: possible effects on health. Nutrition Journal 2011 10:119.

\section{Submit your next manuscript to BioMed Central and take full advantage of:}

- Convenient online submission

- Thorough peer review

- No space constraints or color figure charges

- Immediate publication on acceptance

- Inclusion in PubMed, CAS, Scopus and Google Scholar

- Research which is freely available for redistribution

Submit your manuscript at www.biomedcentral.com/submit 